\title{
ALA-Is It Time for an Alternative?
}

Many academic librarians have been vocal in expressing their unhappiness over the role ACRL plays in the American Library Association. The recent reassessment of ALA goals, which generated the ACONDA recommendations and priorities also reflected membership disenchantment with ALA. To ALA's credit, it should be acknowledged that a concerted effort has been made to implement the ACONDA recommendations. It was unfortunate that the appearance of the ACONDA report coincided closely with the general downturn in the nation's economic fortunes. Because of general budget tightening, implementation of new programs has been extremely difficult. Yet, we must also observe that ALA is essentially the same organization it was five years ago. From the divisions' standpoint, the structure and resource allocating mechanisms remain largely unchanged. The post-ACONDA period has done little to alter the role of ACRL as a division within ALA. Our budget has not been significantly increased, our voice within the ALA Council has been muted, and we still find it difficult to sponsor special purpose programs. If the recent changes have infused a new spirit and vigor within ACRL, I can find scant evidence.

Ralph E. Ellsworth twenty years ago urged ACRL to sever its organizational relationships with ALA. More recently an attempt to establish a federated status was mounted, but the federation idea has not generated any broad base of membership support. Either too few librarians understand the implications of federation, or too many have simply become totally apathetic. Can academic librarians pursue their aspirations within the current organizational structure of ALA? The answer is probably no.

The overall objectives of ALA, including manpower recruitment, social involvement, and censorship are laudable, but they also absorb a large share of the funds available to support program activities. Of course, a considerable proportion of our dues are needed to finance general administrative activities such as journals and membership records. What remains is divided among the many divisions and sections. ACRL's share of the pie comprises a budgetary sliver only; hardly enough to whet our budgetary appetites. Our division consists of twelve-thousand members, and yet we are alloted only one executive secretary, one administrative assistant, and one and a half secretaries to conduct our business. Considering the constraints within which our staff must work, their accomplishments have been quite remarkable. 
The current period is particularly critical to academic librarians. Some librarians are beginning to report that their recently hard-won status has come under attack from academic and state officials. Because sources of funds are rapidly disappearing, more librarians are being asked to reassess and justify their library's role in the educational process. How can a penniless ACRL help develop effective responses?

The central question is whether or not ALA can much longer serve as the home for academic librarians. It appears that the only course is to establish a totally new organization structured to attack the problems peculiar to academic librarians. There are precedents even within our own profession. About forty years ago academic librarians at the large institutions, frustrated by the lack of movement within the parent organization, broke away to form the Association of Research Libraries. Time and events have shown clearly that the achievements of ARL have far exceeded the size of its membership.

ALA's current budgetary policies can only thwart the aspirations of academic librarians at precisely the time when academic librarians are most in need of guidance and support at the national level. Now is the time for academic librarians to consider alternatives to ACRL, if not a federative status, then possibly the AAL (Association of Academic Librarians).

RichaRd M. DOUGHERTY 